\title{
116th APSA Virtual Annual Meeting \& Exhibition Review
}

\author{
ASHLEY VANDE BUNTE | AMERICAN POLITICAL SCIENCE ASSOCIATION \\ KRISTIN KESSLER | AMERICAN POLITICAL SCIENCE ASSOCIATION
}

$\mathrm{P}$ olitical scientists from around the world gathered online from September 9-13, 2020 for the first virtual APSA Annual Meeting due to concerns over the ongoing COVID-19 pandemic. The annual meeting featured nearly 6,000 attendees, 34 exhibitor and sponsor companies, nearly 1,200 panels and 1,300 total events.

Following the decision to transition to a virtual meeting, APSA's 2020 Program Chairs, Efrén Pérez (UCLA) and -. Andra Gillespie (Emory University) issued two $\because$ new calls for proposals to address pressing - social and political issues: "Black Lives, : Black Deaths, and Black Protest: Political : Scientists Respond (Anew) to a Persistent - Challenge" and "Relevance, Quality, and Expedience: Political Science Responds to COVID-19." Pérez noted, "The need for political science to remain timely, relevant, and

"The need for political science to remain timely, relevant, and informative to political events came into incredibly sharp relief this year-and with little warning."

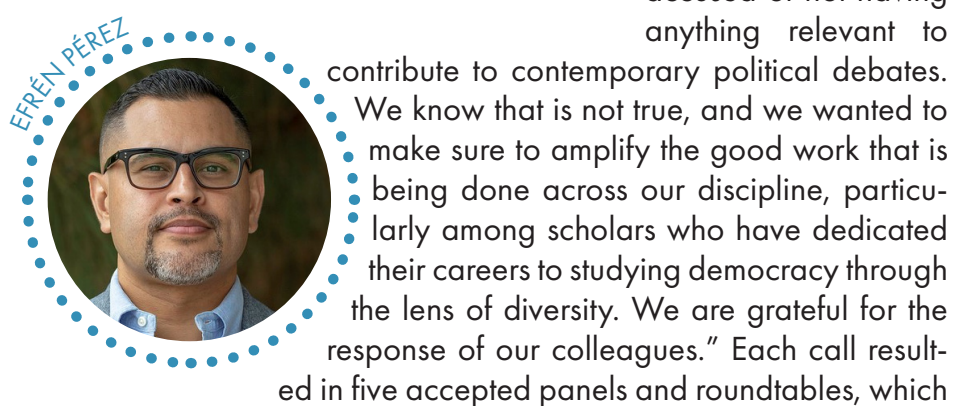
featured presentations from preeminent scholars on race, ethnicity, and politics, and public health and politics.

APSA's pre-conference short courses were held on Tuesday, September 8, and on the morning of Wednesday, September 9. APSA was pleased to allow for complimentary participation in these for conference registrants as part of the virtual meeting. At noon on Wednesday, September 9, the meeting officially kicked off with a presidential address, "Crises, Race, Acknowledgment: The Centrality of Race, Ethnicity and Politics to the Future of Political Science" from APSA President Paula D. McClain. That evening, the APSA Awards Ceremony recognized the recipients of association awards. Due to the virtual format this year, the ceremony was open to all meeting participants for the first time. Both the presidential address and the APSA

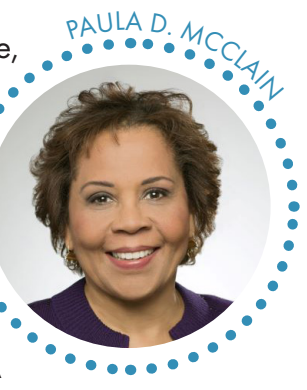
Awards Ceremony are available online for all members.

Thursday, September 10, started with the Career Open House, an opportunity for APSA attendees to connect with departments, institutions, and organizations for information and informal discussions about jobs in political science and other careers that draw on political science training, both on campus and in applied settings. Later, John Mearsheimer (University of Chicago) delivered the James Madison Award Lecture LUCIUS "Liberalism \& Nationalism in Contemporary Amer- ....... B A p, ica." The Annual All-Member Business Meeting, an opportunity for members to learn about the business of the association and express their views, was also held virtually.

Activities continued Friday, September 11, with panels honoring the lives and legacies of renowned political scientists Lucius Barker and Ralph Bunche (both former APSA presidents). Addi-

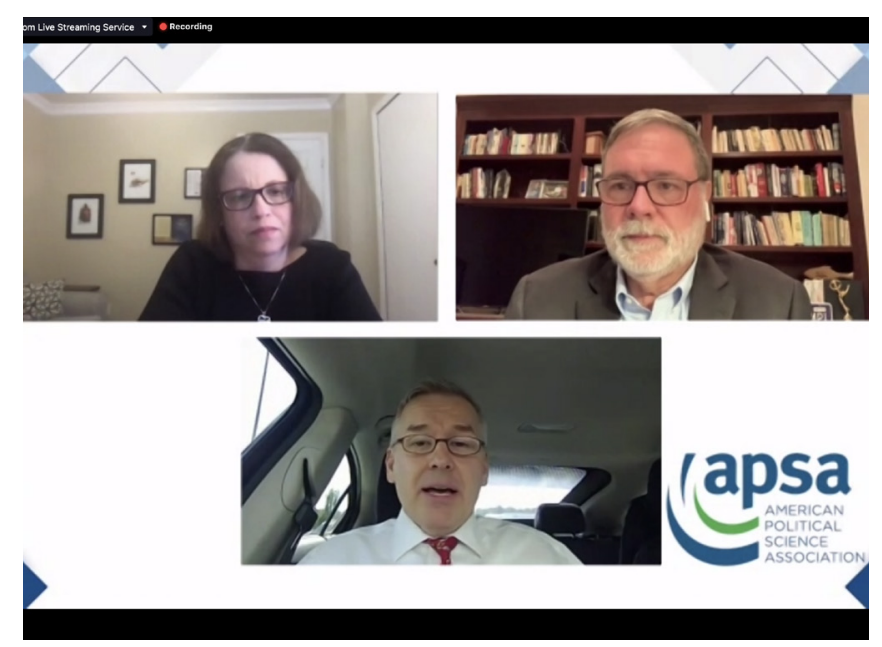

Above: Stella Rouse (University of Maryland) moderates a conversation on polarized governance between Rep. Denny Heck (D-WA) and Rep. Rob Woodall (R-GA). 


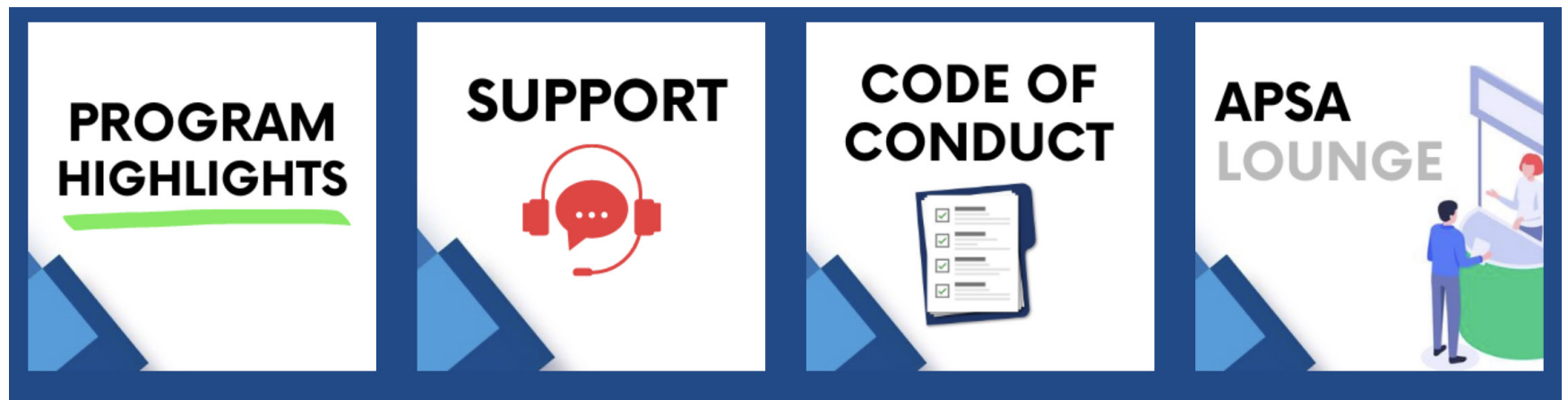

Above: The APSA 2020 Virtual Meeting platform.

tionally, John M. Bryson (University of Minnesota) delivered the John Gaus Award Lecture, "The Future of Strategizing by Public and Nonprofit Organizations," which was followed by a reception. The evening featured many other section and committee business meetings and receptions, including the annual Reception Honoring Women of Color in the Profession.

On Saturday, September 12, APSA was honored to have Reps. Rob Woodall (R-GA) and Denny Heck (D-WA) join attendees for "Perspectives on Polarized Governance: Reflections CHE ... of Two Departing Members of Congress" - a discus-

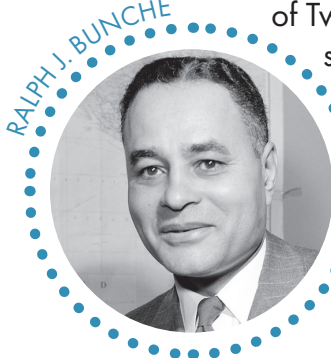
about their perceptions of polarization and - bipartisanship. This session will be made avail: able to all APSA members.

: Saturday also featured the inaugural - Emerging Scholars Symposium. The symposium featured three new categories of presentations reserved for emerging scholars in the field and utilized an innovative panel format similar to PechaKucha and Lightning Rounds. Each scholar had five minutes to present, followed by five minutes of feedback or Q\&A. This format provided a structured framework, giving presenters not only an opportunity to share their research at the world's largest political science meeting, but also an opportunity to develop and enhance research communication skills through a concise presentation. The symposium also coincided with other emerging scholar events on Saturday, including the Graduate School Information Fair and the Gradvate Student Trivia Happy Hour. The third annual TLC at APSA-a "conference within a conference" for the scholarship of teaching and learning-was also held throughout the day. The day wrapped up with additional business meetings and recep-

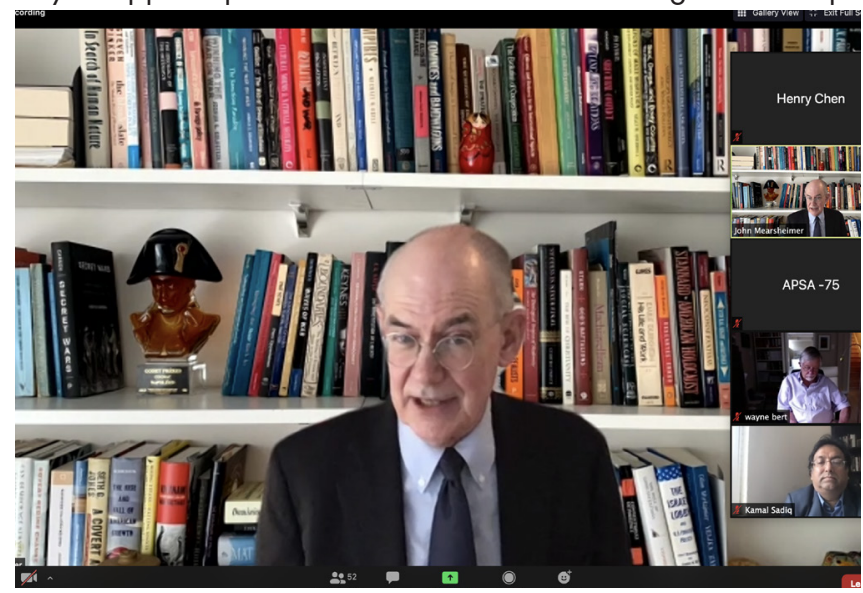

Above: John Mearsheimer delivers the 2020 Madison Award lecture. tions, including the APSA Minority Fellowship Program and RBSI Alumni receptions.

Select meeting sessions will be made available to all APSA members. Conference registrants can currently access all recorded content on the virtual meeting platform until March: https://apsa.conferencecontent.net/login

We wish to thank the membership for making the virtual meeting a success and for its ongoing support in this difficult time. The safety of our community is our top priority, and we are grateful to have been able to convene virtually this year to continue a vibrant and scholarly community of political scientists. We also wish to thank program chairs Efrén Pérez (UCLA) and Andra Gillespie (Emory University), our division chairs, and many other volunteers who helped deliver this important and innovative event to the APSA com-

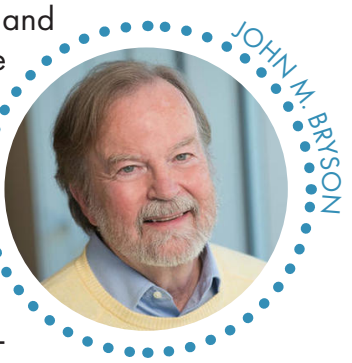
munity.

Looking forward, the 2021 Annual Meeting will be held in Seattle, Washington, from September 30-October 3. At present, we will proceed to plan for a traditional in-person annual meeting. With close monitoring from the World Health Organization (WHO), Centers for Disease Control (CDC), and other public health officials, along with the US State Department Travel Advisories and state and local guidance, we will make necessary adjustments to ensure the health, well-being, and safety of our members. Updates will be provided around the annual meeting as more information and resources continue to develop.

The 2021 theme is "Promoting Pluralism" and can be viewed on the 2021 Annual Meeting website. APSA President Janet Box-Steffensmeier (The Ohio State University) and the 2021 Program Co-chairs, Valeria Sinclair-Chapman (Purdue University) and Dino P. Christenson (Washington University in St. Louis) look forward to your participation in panels and sessions prepared by APSA's 59 divisions and numerous related groups at the 2021 APSA Annual Meeting and Exhibition. -
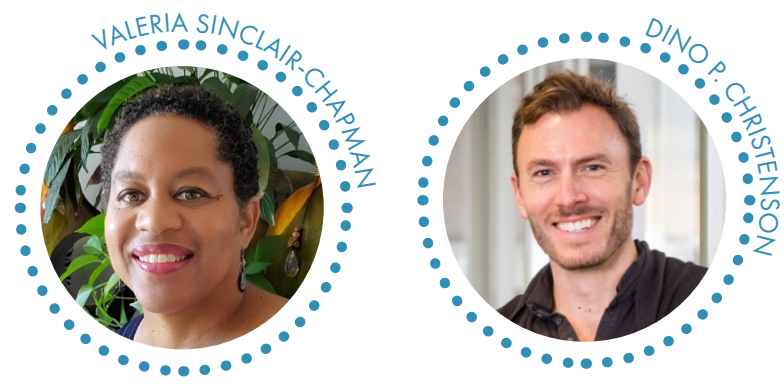